\title{
Experimental Novel Silane System in Adhesion Promotion Between Dental Resin and Pretreated Titanium
}

\author{
Jukka P. Matinlinna • Lippo V. Lassila • \\ Pekka K. Vallittu
}

Received: 13 December 2009 / Accepted: 15 December 2009/Published online: 3 February 2010

(C) Springer Science+Business Media B.V. 2010

\begin{abstract}
Five silane blends were evaluated as experimental adhesion-promoter primers. First, five organosilane monomers (silicon esters), 3-acryloxypropyltrimethoxysilane, 3-methacryloxypropyltrimethoxysilane, 3-glycidoxypropyltrimethoxysilane, tetrakis-(2-ethyloxyethoxy)silane and bis-[3-(triethoxysilyl)propyl]tetrasulfide, were diluted to $1 \%(v / v)$ and blended with a non-functional cross-linking silane, 1,2-bis-(triethoxysilyl)ethane (1\%), in 95\% ethanol. After activation, each blend was applied to silica-coated Ti coupons. A resin based on bis-phenol-A-diglycidyldimethacrylate was then bonded and photo-polymerized as stubs to the pretreated $\mathrm{Ti}$ coupons. Half of the specimens were stored in dry conditions and half were artificially aged by thermo-cycling. The primers containing 3-acryloxypropyltrimethoxysilane and 3-methacryloxypropyltrimethoxysilane produced significantly higher shear bond strength values than the control silane, a standard pre-activated product used in clinical dentistry.
\end{abstract}

Keywords Silica-coating · Silica · Silane coupling agent · Silane monomer Titanium

\footnotetext{
J. P. Matinlinna $(\square)$

Dental Materials Science, Faculty of Dentistry,

The University of Hong Kong,

Hong Kong SAR, People's Republic of China

e-mail: jpmat@hku.hk
}

\section{V. Lassila $\cdot$ P. K. Vallittu}

Department of Biomaterials Science, Institute of Dentistry,

The University of Turku,

Lemminkäisenkatu 2,

20520 Turku, Finland

\section{Introduction}

Silicon dioxide and silane coupling agents have important applications in prosthetic dentistry. For example, prosthetic metal constructions such as substructures for dental bridges and crowns are conventionally pretreated by silica-coating before veneering or cementation [1]. The promotion of adhesion between inorganic materials to organic polymers (e.g. luting cements) is carried out with silane coupling agents. These agents are hybrid inorganic-organic compounds with one or more direct $\equiv \mathrm{Si}-\mathrm{C} \equiv$ bonds, and are also organofunctional silicon esters of the type- $\mathrm{Si}(\mathrm{OR})_{3}$ with hydrolyzable alkoxy groups [2]. Silane-based adhesion promotion, usually with 3-methacryloxypropyltrimethoxysilane, is a custom procedure in prosthetic dentistry for silica-coated materials [3, 4]. Hydrophobic silane monomers need to be activated by hydrolysis for subsequent condensation to take place (Fig. 1), usually with a catalyst (e.g. $\mathrm{H}^{+}$ions). During hydrolysis, the corresponding aliphatic alcohol is released and the silane becomes an intermediary hydrophilic silanol that gets deposited onto the substrate as a connecting siloxane film between the inorganic and organic matrices (Fig. 2) [5]. However, the hydrolytic stability of silane-aided bonding, and thus longevity of the restoration in oral humid conditions, is an ongoing concern that requires more research $[6,7]$.

The introduction of blends of organofunctional silane monomers and cross-linking silanes has made it possible for many resin-composite systems to achieve considerable hydrolytic stability and mechanical strength [8]. The crosslinking silane can be non-functional (Fig. 3), possessing only hydrolyzable alkoxy groups, as in bis-1,2-(triethoxysilyl)ethane, which is often combined at a $1: 5$ to $1: 10$ ratio with a functional silane monomer to prevent steel corrosion 
Fig. 1 A chemical equation showing the complete hydrolysis of 3-methacryloxypropyltrimethoxysilane<smiles>C=C(C)C(=O)OCCC[Si](OC)(OC)OC</smiles><smiles></smiles>

[9]. The thickness of the siloxane film that forms during curing strongly depends on the silane concentration [8]. In addition, an interpenetrating polymer network is understood to form between the adhesion-promoting siloxane film and resin-composite (Fig. 2) [10].

Organofunctional groups in the silane molecule other than methacrylate may further enhance bonding and adhesion. Several such silanes have recently been evaluated as coupling agents in dental resin-composites $[6,11]$ and as adhesion promoters for silica-coated $\mathrm{Ti}$ [12] or polished $\mathrm{Ti}$ [13]. In vitro results of a novel silane system of a functional silane and a cross-linking silane suggest that the system's significantly enhanced adhesion could be useful in dental materials applications $[14,15]$.

In this study we have evaluated novel silane systems based on a primer of bis-1,2-(triethoxysilyl)ethane blended with one of five functional silane monomers: 3-acryloxypropyltrimethoxysilane [16], 3-methacryloxypropyltrimethoxysilane [17], 3-glycidoxypropyltrimethoxysilane, tetrakis-(2-methacryloxyethoxy)silane and bis-[3-(triethoxysilyl)propyl]tetrasulfide. The glycidoxy functionality was selected because of its ring-opening chemistry and tetrasulfide because of its long chain and sulphur reactivity. The fifth silane was included because the four vinyl double bonds in its methacrylate groups might act as a cross-linking silane (Fig. 3). Our hypothesis was that any of these five functional silane primers in a blend with a cross-linking silane produces superior bonding of a bis-GMA resin onto silica-coated Ti, when compared with a standard, pre-activated 3-methacryloxypropyltrimethoxysilane [4] product. A non-filled resin system based on the experimental bis-phenol-A-

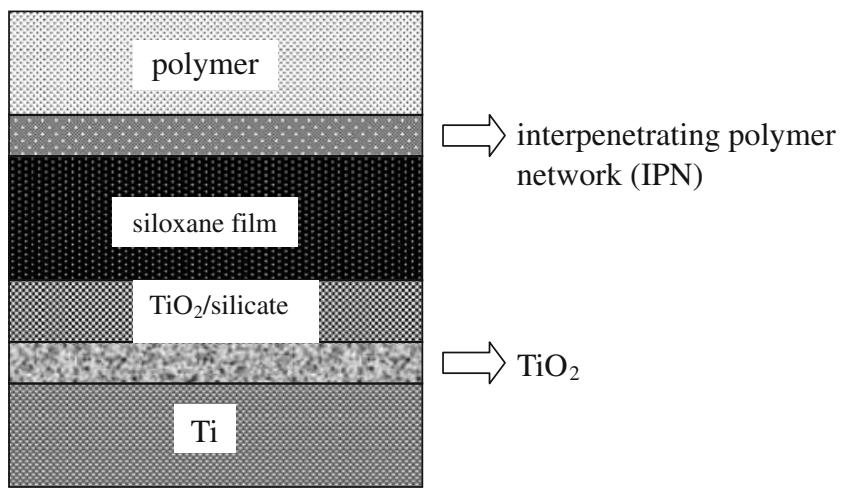

Fig. 2 Illustration of the phases/layers in silane-aided bonding between polymer and silica-coated Ti substrate diglycidyldimethacrylate (bis-GMA) was used in the assay because most modern dental resin-composite cements are chemically based on this system [18]. Similarly, Ti was studied because it is a widely used biomaterial - for example, in crown implants and bridge substructures [14, 19-21].

\section{Experimental}

The materials used in this study are listed in Table 1; all percentages are by volume. The experimental resin consisted of $78.4 \%$ bis-GMA, $19.6 \%$ methylmethacrylate, $1.0 \% 2$-(dimethylamino)ethylmethacrylate and $1.0 \%( \pm)$ camphorquinone [18], blended together and prepared in polythene syringes. The syringes were covered with aluminum foil and allowed to stabilize for $72 \mathrm{~h}$ in the dark at about $7{ }^{\circ} \mathrm{C}$. The resin was used after resting at room temperature (RT) for $30 \mathrm{~min}[12,15]$. A sheet of CP grade 2 Ti of 1-mm thickness was cut into coupons of $20 \times 40 \mathrm{~mm}^{2}$ $(n=24)$. The upper half of the surface was grit-blasted with special silica-coated alumina sand at $300 \mathrm{kPa}$ for $10 \mathrm{~s}$ from a perpendicular distance of $10 \mathrm{~mm}$ (Rocatec ${ }^{\mathrm{TM}}$ system; ESPE, Seefeld, Germany). The silica-coated Ti coupons were cleaned in ethanol in an ultrasonic bath, air-dried at RT and randomly divided into 12 study groups ( $n=2$ each) (Fig. 4).

Five experimental silane primers were prepared in $95 \%$ ethanol and $5 \%$ deionized water, and adjusted to $\mathrm{pH} 4.5$ with $1 \mathrm{M}$ acetic acid. First, a $1 \%$ solution of 1,2-bis(triethoxysilyl)ethane was made and activated by hydrolysis for $23 \mathrm{~h}$ at RT; then the organofunctional silane was added to reach $1 \%$, and the blends were allowed to stabilize for an additional $1 \mathrm{~h}$ at RT before use. A commercially available pre-activated silane product was used as the control [4].

The five primers and control were applied onto the silica-coated $\mathrm{Ti}$ with a fine brush as one coat according to the usual clinical procedure, and allowed to react (dry) for $3 \mathrm{~min}$. The bis-GMA-based resin was transferred into polythene molds to form resin stubs with a diameter of $3.6 \mathrm{~mm}$ and a height of $4 \mathrm{~mm}$. Five resin stubs in duplicate were evenly placed on the upper horizontal borders of the 24 pretreated $\mathrm{Ti}$ coupons. The stubs were then photopolymerized with an Optilux 501 lamp (SDS Kerr, Danbury, USA) at $490 \mathrm{~mW} \mathrm{~cm}^{-2}$ for $40 \mathrm{~s}$. A final polymerization step was immediately performed in a Visio ${ }^{\circledR}$ BETA Vario photocuring vacuum unit (ESPE, Seefeld, Germany) for $15 \mathrm{~min}$. The mold was then removed carefully while the cured resin 
Fig. 3 Organofunctional silane monomers: a 3-acryloxypropyltrimethoxysilane, b 3-methacryloxypropyltrimethoxysilane, c 3-glycidoxypropyltrimethoxysilane, d tetrakis-(2-methacryloxyethoxy)silane,

e bis-[3-(triethoxysilyl)propyl] tetrasulfide, a cross-linking silane: $\mathbf{f} 1$,

2-bis-(triethoxysilyl)ethane<smiles>C=CC(=O)OCCC[Si](OC)(OC)OC</smiles>

a)

b)<smiles>CO[Si](CCCOCC1CO1)(OC)OC</smiles><smiles>C=C(C)C(=O)OCCO[Si](OCCOC(=O)C(=C)C)(OCCOC(=O)C(=C)C)OCCOC(=O)C(=C)C</smiles>

c)

d)<smiles>CCO[Si](CCCSSSSCCC[Si]1(OCC)OCCCO1)(OC)OCC</smiles>

e)<smiles>CCO[Si](CC[Si](OCC)(OCC)OCC)(OCC)OCC</smiles>

f) stubs were pressed against the substrate with a hand instrument. One half of the Ti-resin specimens were kept in a desiccator for $24 \mathrm{~h}$ prior to shear bond strength testing; the other half was subjected to thermo-cycling to simulate aging $[12,14,22]$. Thermo-cycling took place for 6,000 cycles between $5^{\circ}$ and $55^{\circ} \mathrm{C}$, with a standard dwelling time of $30 \mathrm{~s}$ and a transfer time of $2 \mathrm{~s}$ (Heto CBN 18-30 baths; Allerø, Denmark). The thermo-cycled specimens were kept in a water bath at $37^{\circ} \mathrm{C}$ before testing.

Shear bond strength testing was done with a universal material testing machine (LRX ${ }^{\circledR}$; Lloyd Instruments, Fareham, UK) at a constant cross-head speed of $1.0 \mathrm{~mm} \mathrm{~min}{ }^{-1}$ until fracture occurred at the stub-adhesive interface. The shear bond strength (in MPa) was calculated by dividing the highest force applied (in $\mathrm{N}$ ) by the area of the resin stub (diameter, $3.6 \mathrm{~mm}$ ) [22]. Failed thermo-cycled specimens were gold sputter-coated, and examined with scanning electron microscopy (XL20; Philips, Eindhoven, Netherlands). When $33 \%$ of the resin stub was left on the Ti surface, the failure type was "adhesive", when $>33 \%$ but $<66 \%$ remained, it was "mixed failure" and when $>66 \%$ remained, it was "cohesive".

Differences in shear bond strength between groups were tested with analysis of variance (ANOVA) using the Statistical Package for the Social Sciences (SPSS, Chicago, IL, USA). Multiple comparisons were performed with Tukey's test and Levene's test of equality of error variances, with statistical significance set at $p=0.001$. The $t$-test was used to evaluate obtained values that were numerically close to each other. 
Table 1 Materials used

\begin{tabular}{lllll}
\hline Material, name & Abbreviation & Manufactured by & Purity [\%] & Batch number \\
\hline Titanium & Ti & Permascand, Ljungaverk, Sweden & $>99$ & AS TM B26589 \\
Ethanolum Anhydricum & Ethanol & Primalco, Helsinki, Finland & 99 & 030305 \\
Acetic acid & N/A & Merck, Darmstadt, Germany & 100 & K12716063 \\
3-Methacryloxypropyltrimethoxysilane & MPS & Dow Corning, Midland, MI, USA & $>95$ & 0002015730 \\
3-Acryloxypropyltrimethoxysilane & ACPS & Gelest, Tullytown, PA, USA & 95 & 5 C-6412 \\
3-Glycidoxypropyltrimethoxysilane & GPS & Dow Corning, Midland, MI, USA & 95 & 0001677214 \\
Tetrakis-(2-methacryloxyethoxy)silane & TEXS & Gelest, Tullytown, PA, USA & 90 & N/A \\
Bis-[3-(triethoxysilyl)propyl]tetrasulfide & TSEF & Gelest, Tullytown, PA, USA & 95 & $3 \mathrm{~A}-2236$ \\
1,2-bis-(triethoxysilyl)ethane & BTSE & Gelest, Tullytown, PA, USA & 100 & $4 \mathrm{R}-4325$ \\
ESPE Sil prehydrolyzed silane coupling agent & N/A & 3M ESPE, Seefeld, Germany & N/A & 256464 \\
Rocatec ${ }^{\mathbb{B}}$ Plus sand & N/A & 3M ESPE, Seefeld, Germany & $>95$ & Not available \\
Bis-Phenol-A-diglydicyldimethacrylate & bis-GMA & Röhm, Darmstadt, Germany & $>95$ & Not available \\
Methylmethacrylate & MMA & Fluka, Buchs, Switzerland & $>99$ & $436935 / 141702$ \\
2-(Dimethylamino)ethylmethacrylate & DMAEMA & Sigma-Aldrich, Steinheim,Germany & 98 & BO05923KU \\
( \pm )-Camphorquinone & CQ & Fluka, Buchs, Switzerland & $>98$ & $395656 / 1$
\end{tabular}
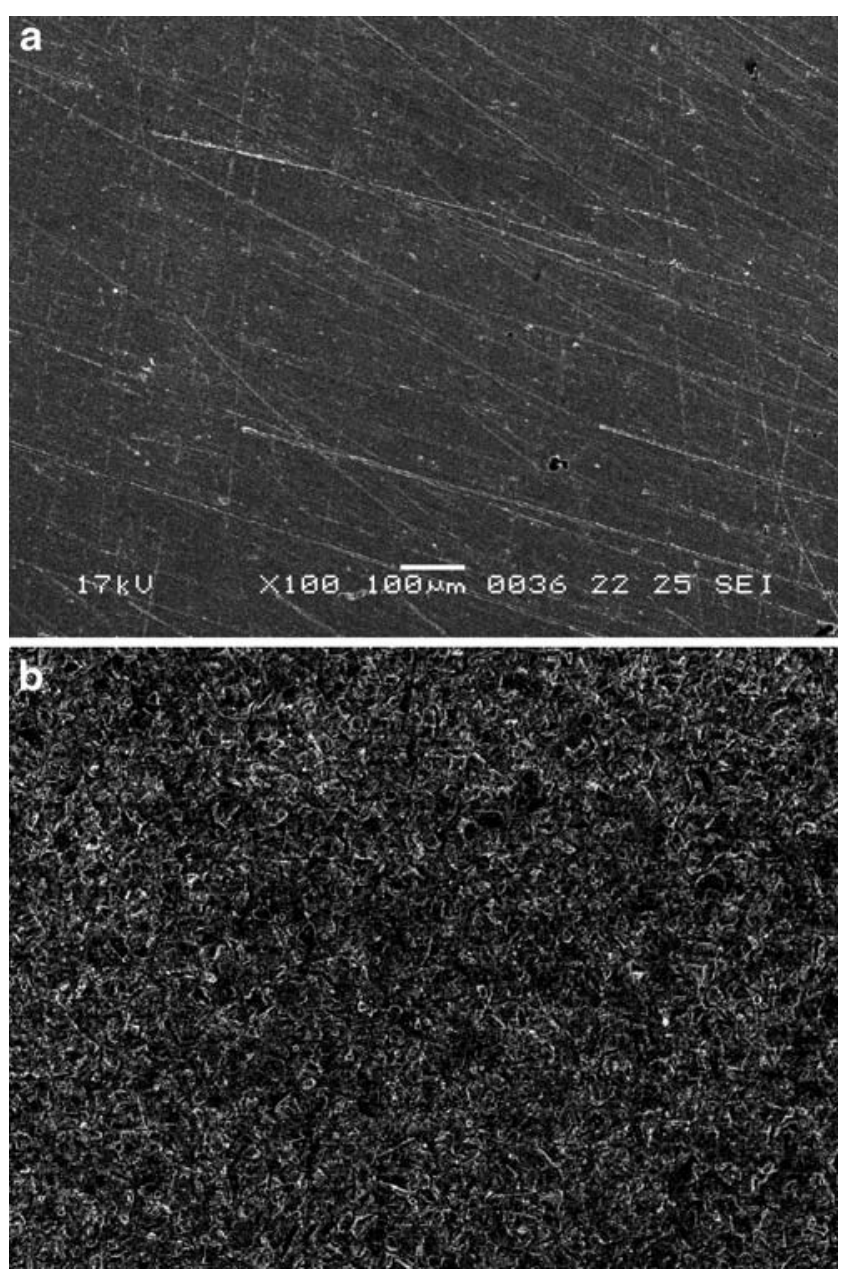

Fig. 4 Ti coupons, a polished with 600 grit $\mathrm{SiC}$ paper, and b silicacoated (both at the same scale)

\section{Results and Discussion}

This study assessed the effects of five silane blends on resin-Ti adhesion. Thermo-cycling was an additional variable of interest, because test conditions are thought to best simulate the clinical situation in dentistry [22]. In general, the type of functional silane $(p<0.001)$ and storage conditions $(p<0.001)$ significantly affected the shear bond strength (Table 2, Fig. 5). The reduction in the strength values due to thermo-cycling for all specimen groups was substantial and can be explained by the difference between the thermal expansion coefficients of $\mathrm{Ti}$ (about $12 /{ }^{\circ} \mathrm{C} \times 10^{6}$ ) and the experimental unfilled methacrylate resin (although not measured, it approximates the value for acrylic denture resin, about $76 /{ }^{\circ} \mathrm{C} \times 10^{6}$ ) [23]. This difference might also explain the relatively high standard deviations in bond strength results of thermo-cycled specimens. The observed effects are expected because the vinyl group in the acrylate moiety is intrinsically much more reactive than the vinyl group in the methacrylate moiety. In vitro studies have suggested that acrylate silane alone promotes resin adhesion to silica-coated $\mathrm{Ti}[16]$ and blending with a cross-linking silane improves E-glass fiber silanization in composites [24]. In addition, 3-acryloxypropyltrimethoxysilane is currently used in optical fiber and UV coatings, while 3-methacryloxypropyltrimethoxysilane is a widely used coupling agent in glass-fiber composites.

The highest shear bond strength was obtained for samples treated with the 3-acryloxypropyltrimethoxysilane + bis-(triethoxysilylpropyl)ethane blend, both for samples that underwent thermo-cycling and for those that underwent dry storage, at $8.7(\mathrm{SD}, 2.4) \mathrm{MPa}$ and $23.0(6.0) \mathrm{MPa}$, 
Table 2 Shear bond strength as mean (standard deviation [SD]) after dry storage or thermocycling and $t$ observed failure type after thermo-cyling ( $n=10$ per group). Key: see Fig. 5 caption

\begin{tabular}{|c|c|c|c|c|c|}
\hline \multirow[t]{2}{*}{ Silane (silanes) used } & \multicolumn{2}{|c|}{ Shear bond strength (SD) $[\mathrm{MPa}]$} & \multirow{2}{*}{$\begin{array}{l}\text { Cohesive } \\
\text { failure }[\%]\end{array}$} & \multirow{2}{*}{$\begin{array}{l}\text { Mixed } \\
\text { failure [\%] }\end{array}$} & \multirow{2}{*}{$\begin{array}{l}\text { Adhesive } \\
\text { failure }[\%]\end{array}$} \\
\hline & Dry storage & Thermo-cycling & & & \\
\hline Control ESPE Sil & $10.6(2.1)$ & $4.7(1.9)$ & 80 & 20 & 0 \\
\hline $\mathrm{ACPS}+\mathrm{BTSE}$ & $23.0(6.0)$ & $8.7(2.4)$ & 60 & 40 & 0 \\
\hline $\mathrm{MPS}+\mathrm{BTSE}$ & $20.0(6.3)$ & $6.6(2.6)$ & 80 & 20 & 0 \\
\hline GPS + BTSE & $11.1(1.9)$ & $3.8(1.4)$ & 0 & 0 & 100 \\
\hline TEXS + BTSE & $8.6(1.6)$ & $2.8(1.4)$ & 0 & 0 & 100 \\
\hline TSEF + BTSE & $6.0(2.1)$ & $0.0(0.0)$ & 0 & 0 & 100 \\
\hline
\end{tabular}

respectively. The lowest shear bond strength for dry samples, 6.0 (2.1) $\mathrm{MPa}$, was obtained when the functional silane was bis-[3-(triethoxysilyl)propyl]tetrasulfide, and for thermocycled samples, it was 2.8 (1.4) $\mathrm{MPa}$, obtained when the functional silane was tetrakis-(2-methacryloxyethoxy)silane. The primers containing 3-acryloxypropyltrimethoxysilane and 3-methacryloxypropyltrimethoxysilane produced significantly higher shear bond strength values than the control silane.

Three blends, containing the functional silanes of 3-acryloxypropyltrimethoxysilane, 3-methacryloxypropyltrimethoxysilane and bis-[3-(triethoxysilyl)propyl]tetrasulfide, produced shear bond strength values that exceeded the critical threshold of $5 \mathrm{MPa}$, as defined and set for dental materials by the ISO Standard 10477 Amendment [22]. Surprisingly, the control silane, which contained 3methacryloxypropyltrimethoxysilane and was a fresh, unopened bottle of a type of silane coupling agent in regular use in clinical dentistry $[3,4]$, resulted in bonding values that were below the critical threshold.

Overall, the results showed a trend by which the adhesive type of failure after thermo-cycling was predominant for shear bond strength values of less than $6 \mathrm{MPa}$. The low bonding results and 100\% score of adhesive failure for specimens that used blends containing 3-glycidoxy- propyltrimethoxysilane, tetrakis-(2-methacryloxyethoxy) silane and bis-[3-(triethoxysilyl)propyl]tetrasulfide showed that these silane blends promoted the least adhesion. Although tetrakis-(2-methacryloxyethoxy)silane cannot hydrolyze any of its four vinyl bonds, it was allowed to "react" for $1 \mathrm{~h}$ as with the other functional silanes and even promoted adhesion more than bis(triethoxysilylpropyl)ethane. The former's spatial configuration and molecular entanglement with resin monomers may explain this finding. In the case of the control silane (not cross-linked and without a functional silane), a high proportion of cohesive failures was observed with low shear bond strength values $(4.7 \mathrm{MPa})$. This finding suggests that the cohesive strength of the resin-composite system was somehow reduced during polymerization when in close contact to the control silane.

The prerequisite for bonding of resins to metals is silicacoating followed by silanization. Monomer conversion was not measured, but it is reported to be about $64 \%$ for the non-filled resin used in this study, as based on characterization data of experimental bis-GMA resin [25, 26]. Hydrolysis within $24 \mathrm{~h}$ was selected for the cross-linker silane [8,9] and $1 \mathrm{~h}$ for functional silanes [12-17], although it is accepted that silane coupling agents need not hydrolyze completely. In particular, functional trialkoxy silanes
Fig. 5 Shear bond strength (in $\mathrm{MPa}$ ) after dry storage and after thermo-cycling. Key: MPS = 3-methacryloxypropyltrimethoxysilane, BTSE = 1,2-bis-(triethoxysilyl)ethane, ACPS = 3-acryloxypropyltrimethoxysilane, GPS = 3-glycidoxypropyltrimethoxysilane, TEXS = tetrakis-(2-methacryloxyethoxy) silane, TSEF = bis-[3-(triethoxysilyl)propyl]tetrasulfide

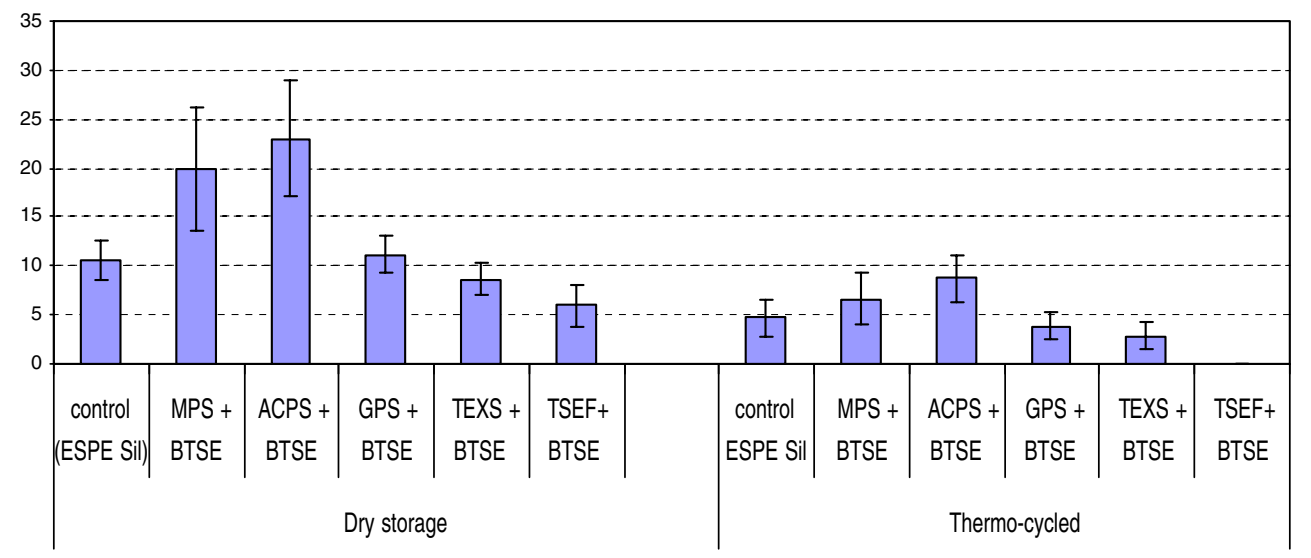


hydrolyze sufficiently during $1 \mathrm{~h}$ or even less [12-15]. Scanning electron microscopy, however, showed a dramatic change in surface texture and morphology, and thus in surface area. Silica-coating was performed in the same manner on all samples, and Ti coupons were designated to study groups randomly, so it was expected that there would not be any significant differences in the silica content on Ti. We did not measure the roughness of Ti with atomic force microscopy or analyze the chemical composition of silicacoated Ti because these have been previously reported [12]. About 20 atomic- $\%$ of $\mathrm{Si}$ can be achieved on $\mathrm{Ti}$, as shown in a study using the same silica-coating procedure as used in this study [12]. Although silica content is decisive for the formation of $\equiv \mathrm{Si}-\mathrm{O}-\mathrm{Si} \equiv$ bonds, there is also some FTIR evidence of $\equiv \mathrm{Ti}-\mathrm{O}-\mathrm{Si} \equiv$ bond formation during direct silanization without silica-coating [27].

Finally, shear bond strength testing [28] and thermo-cycling as an aging method for in vitro testing of resin-bonded restorations in dentistry are based on widely used standards, but are sometimes criticized. Still, shear bond strength data might be clinically interesting and relevant, because they generally correspond well to composite bonding to enamel using some bonding systems (10-12 MPa), or composite bonding to dentin using hydroxyethylmethacrylate and glutaraldehyde (11-17 MPa) [23]. Unfortunately, there are no published comparable data on the shear bond strengths in other technical applications using silane blends.

\section{Conclusions}

This study has evaluated five different functional activated silane monomers blended with a cross-linking silane. After thermo-cycling, all shear bond strength values were lowered significantly and all exceeded control values. The shear bond strength values obtained with 3-acryloxypropyltrimethoxysilane and 1,2-bis-(triethoxysilyl)ethane, were the highest. There were significant differences between the shear bond strength values obtained with different silane blends.

Acknowledgements The authors wish to thank Dr. Barry Arkles (Gelest Inc., Tullytown, PA, USA) for donating the silane monomers and Dr. Trevor Lane (The University of Hong Kong) for editing the manuscript.

\section{References}

1. Meiners H, Herrmann R, Spitzbarth S (1990) Dental Labor 38:185

2. Rosen MR (1978) J Coat Technol 50:70

3. Barghi N (2000) Compend Cont Educ Dent 21:659

4. Matinlinna J, Lassila LVJ, Özcan M, Yli-Urpo A, Vallittu PK (2004) Int J Prosthod 17:155

5. Plueddemann EP (1970) J Adhes 2:184

6. Nihei T, Kurata S, Kondo Y, Umemoto K, Yoshino N, Teranaka T (2002) J Dent Res 81:482

7. Matinlinna JP, Vallittu PK (2007) J Contemp Dent Pract 8(2):1

8. van Ooij WJ, Zhu DQ, Prasad G, Jayaseelan S, Fu Y, Teredesai N (2000) Surf Engin 16:386

9. Sundararajan PG, van Ooij WJ (2000) Surf Engin 16:315

10. Klempner D, Sperling LH, Utracki LA (1994) Interpenetrating polymer networks. Advances in Chemical Sciences, vol. 239. Am Chem Soc, Washington

11. Wilson KS, Antonucci JM (2006) Dent Mater 22:995

12. Matinlinna JP, Lassila LVJ, Kangasniemi I, Vallittu PK (2005) J Dent Res 84:360

13. Matinlinna J, Özcan M, Lassila LVJ, Vallittu PK (2004) Dent Mater 20:804

14. Matinlinna JP, Lassila LVJ, Vallittu PK (2006) J Dent 34:436

15. Matinlinna JP, Lassila LVJ, Vallittu PK (2006) J Dent 34:740

16. Matinlinna JP, Lassila LVJ, Vallittu PK (2007) Dent Mater 23:1173

17. Matinlinna JP, Lassila LVJ, Vallittu PK (2007) Acta Odontol Scand 65:44

18. Bowen RL, Marjenhoff WA (1992) Advis Dent Res 6:44

19. Kern M, Thompson VP (1994) J Dent 22:300

20. Kern M, Thompson VP (1995) J Prosthodont 4:16

21. Matinlinna JP, Lassila LVJ, Kangasniemi I, Yli-Urpo A, Vallittu PK (2005) Dent Mater 21:287

22. International Organization for Standardization (ISO) (1996) Dentistry-polymer-based crown and bridge materials, Amendment 1996; ISO 10477

23. O'Brien WJ (2002) Dental materials and their selection, 3rd edn. Quintessence, Carol Stream, pp 313-314

24. Matinlinna JP, Dahl JE, Lassila LVJ, Vallittu PK (2007) In: Mittal KL (ed) Silanes and other coupling agents, vol. 4. pp 83-97

25. Viljanen E, Skrifvars M, Vallittu PK (2004) J Appl Polymer Sci 93(04):1908

26. Puska M, Lassila L, Seppälä J, Vallittu P, Matinlinna J (2009) J Adhes Sci Techn 23:991

27. Matinlinna JP, Özcan M, Lassila LVJ, Vallittu PK (2004) Dent Mater 20:804

28. Söderholm K-J (2009) J Adhes Sci Techn 23:973 